Case Series

\title{
Solid Pseudopapillary Pancreatic Tumor - Tumor of
} Frantz

\author{
Rossen Madjov, Plamen Chernopolsky, Vasil Bozhkov and Madjova V \\ 2nd Department of Surgery, University Hospital "St. Marina", Varna, Bulgaria
}

\section{Article Info}

\author{
*Corresponding author: \\ Vasil Bozhkov \\ Associate Professor \\ 2nd Department of Surgery \\ University Hospital "St. Marina" \\ 1st Hr. Smirnensky blvd \\ Varna-9010 \\ Bulgaria \\ E-mail: bojkov7@gmail.com
}

Received: April 24, 2019

Accepted: July 10, 2019

Published: July 18, 2019

Citation: Madjov R, Chernopolsky P, Bozhkov V, Madjova V. Solid Pseudopapillary Pancreatic Tumor - Tumor of Frantz. Madridge J Surg. 2019; 2(1): 67-71.

doi: 10.18689/mjs-1000116

Copyright: @ 2019 The Author(s). This work is licensed under a Creative Commons Attribution 4.0 International License, which permits unrestricted use, distribution, and reproduction in any medium, provided the original work is properly cited.

Published by Madridge Publishers

\begin{abstract}
Introduction: Solid cystic pseudopapillary tumor, known also as tumor of Frantz, is a rare primary neoplasm of the pancreas with unknown etiology, appearing predominantly in young females. Characterized by a lack of clinical symptomatology and can reach large sizes before final diagnosis. Degenerative cystic changes and hemorrhagic areas are typical and the most common clinical manifestation is a cystic pancreatic tumor, palpable mass and uncharacteristic abdominal pain. Although resection of the tumor provides a 5 -year survival rate almost $90 \%$, local recurrence or distant metastases can occur in significant number of patients. Patients with solid pseudopapillary cystic tumors have much better prognosis, so it is important to distinguish it from other pancreatic neoplasms.
\end{abstract}

Aim: The aim of this study is to present three cases of solid pseudopapillary tumor of pancreas occurring in female patients. The common in the clinical presentation was discomfort and pain in the upper abdomen, no past medical history of biliary pathology. Mid portion resection of the pancreas was performed in all of the three patients followed by histopathological examination which confirmed the diagnosis pseudopapillary tumor of pancreas.

Conclusions: Solid pseudopapillary tumor of the pancreas is a rare primary neoplasm with unknown etiology, developing most commonly in young females. Prognosis even for patients with SPPT and with treated liver metastases varies from 6 months up to more than 15 years. The role of chemotherapy, radiotherapy, TAE, TACE, radiofrequency is still under investigation.

Keywords: Solid pseudopapillary pancreatic tumor; Tumor of Frantz; Pancreatic resection; Immunohistochemistry; Prognosis.

\section{Introduction}

Solid pseudopapillary tumor (SPT) is a rare pathological entity of the pancreas (accounting for 1.0-2.0\% of primary tumors), characterized with low malignant potential and still uncertain cellular origin. Most commonly found in young females. First report in the literature was made by Frantz in 1959, with description of three cases. Although SPT classification to epithelial pancreatic tumors, in many of the cases, cytokeratin production is not observed, but neuroendocrine differentiation is characteristic [1]. Tumors of Frantz, solid cystic tumor, papillary and solid epithelial neoplasy, are some of the other titles are given to SPT. The term SPPT (solid pseudopapillary pancreatic tumor) was introduced in 1996 by the WHO for the International classification of tumors of the exocrine pancreas. Although increasing recognition of this tumor during last two decades, its pathogenesis and apparent therapeutic algorithm still remains uncertain [2]. 


\section{Clinical Cases}

\section{Case 1}

Woman of 25 years, hospitalized at the clinic with a diagnosis of neuroendocrine tumor of the pancreas. Complaints upon admission of the patient have been observed around 3 months-abdominal pain upper half, a strong left and back irradiation, the occurrence of discrete swelling of face and hands, repeatedly raising the temperature to $37.6^{\circ} \mathrm{C}$, increased sweating with odor perspiration.

In the instrumental imaging studies (US and CT scan figure 1) a hypodense formation was established in the transition to the head/body (neck) of the pancreas, wellencapsulated lesion (sharp contour lines), with varying solid and cystic components owing to hemorrhagic degeneration, sized-67/60/45 mm. Following contrast material administration, enhanced solid areas (with a density about 50XE) are typically noted peripherally, whereas cystic spaces (density XE 18-20) are more centrally located. Slightly extended D. Wirsungianus. FNA/performed under CT control/-data suggestive for neuroendocrine tumor of the pancreas.

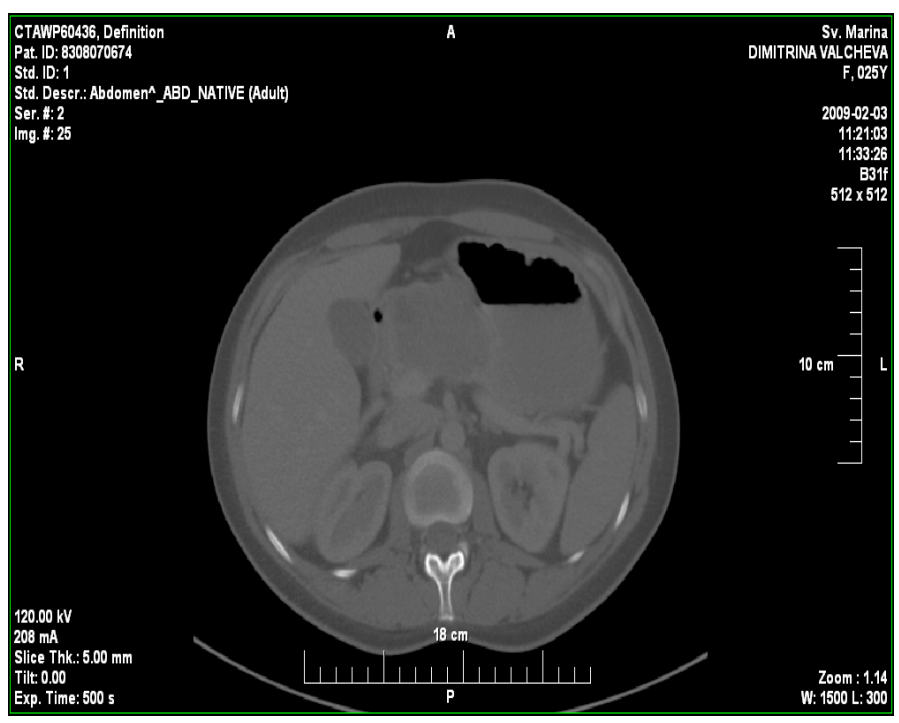

Figure 1. D.V. 25 years CT scan - Tu mass in pancreas

Intra-operative: Oval tumor mass, sizes-8.5/6.0/4.5 cm. Motley (gaily-coloured) cut surface with whitish, yellowish areas and bleeding. Radical resection of mid portion of the pancreas including tumor was performed $-1.0 \mathrm{~cm}$ from the duodenum and $4.5-5.0 \mathrm{~cm}$. remaining stamp left of the pancreatic tail. Pancreatogastric anastomosis+stent were performed. No complications postoperatively and the patient was discharged. She is symptom free and no recurrence for 44 months.

\section{Case 2}

31 year woman admitted with an intra-abdominal tumor mass, located in the body of the pancreas. She was a febrile, with a normal pulse and blood pressure. Slight upper abdominal discomfort. No history of hepato-biliary or pancreatic disease or other malignancy in her family. There was a mild upper/left abdominal tenderness on palpation. Abdominal US (Figure 2) and CT scan showed a well-defined heterogeneous mass, located in the head/body of the pancreas, with a definite capsule. Performed also MRI and PET CT scan-data for tumor mass in the pancreas.

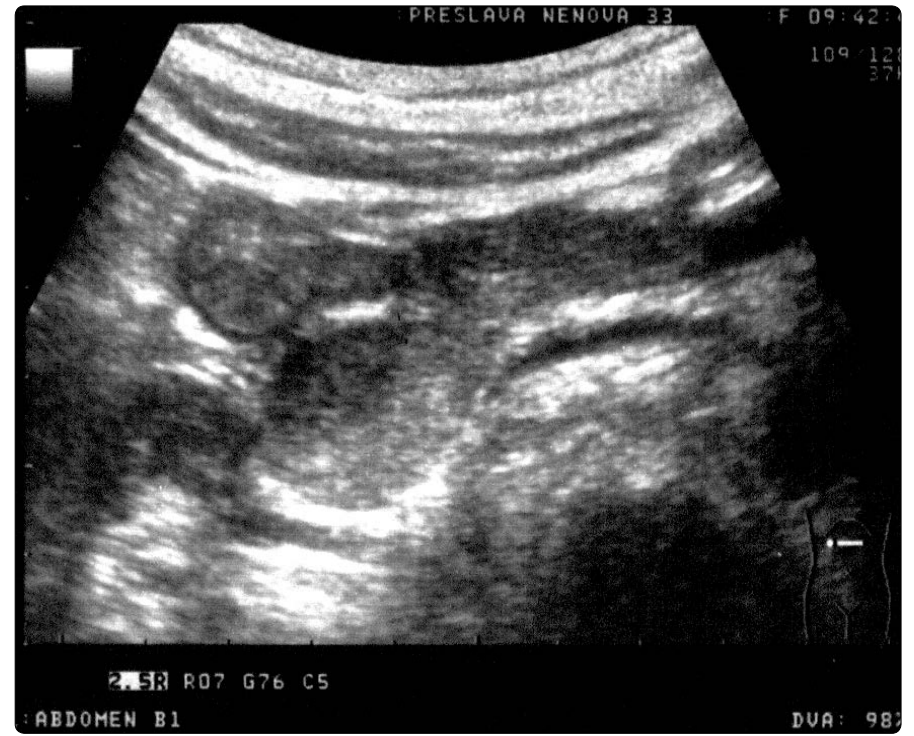

Figure 2. P.N. 31 years US - Tu mass in pancreas.

Intra-operatively: A rounded tumor mass, sized $5.0 / 6.0 \mathrm{~cm}$. Radical resection of the mid portion of the pancreas and pancreato-gastric anastomosis performed. Patient is symptom free for 38 months.

In histopathological examination of operative specimensencapsulated tumor, made up of solid areas, surrounding vessels and connective tissue, with disorganization and pseudocystic transformation (Figure 3), forming a pseudopapillary structures (Figure 4) of medium-sized polygonal, rounded and elongated cells with oval nuclei, some of the cells - a bright peripheral cytoplasm and nucleus. Examination founds clusters of macrophages and large deposits of cholesterol giant cell granulomatous reaction and calcification. In the periphery of the expansion unit-sharply distinct nodulus, $3 \mathrm{~cm}$ in diameter, with a homogeneous structure and strands of small trabecules, a monotonous appearance of endocrine cells, thin-walled vessels and soft fibrous strands. $\mathrm{IHH}$ typing - weak expression of Chromogranin, mainly in the nodulus; expression of S-100 in antigen presenting cells; Pancytokeratin-weak, mainly expressed in neuroendocrine component; diffuse expression of Vimentin (Figure 5) and nuclear expression of Progesterone (Figure 6), low (under 10\%), Ki nuclear activity.

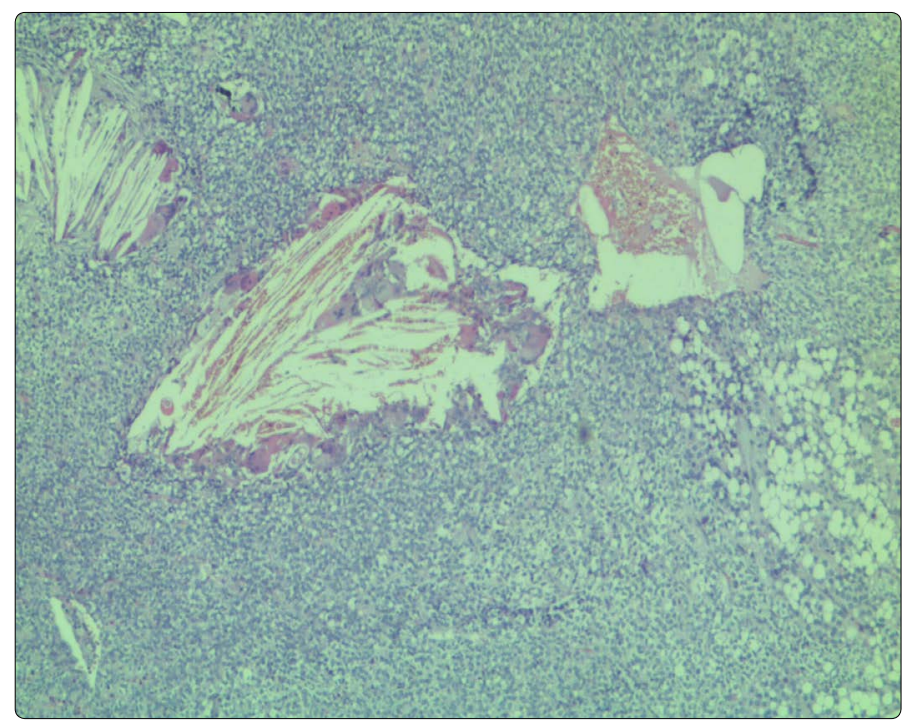

Figure 3. Pseudopapillary tumor of the pancreas. 


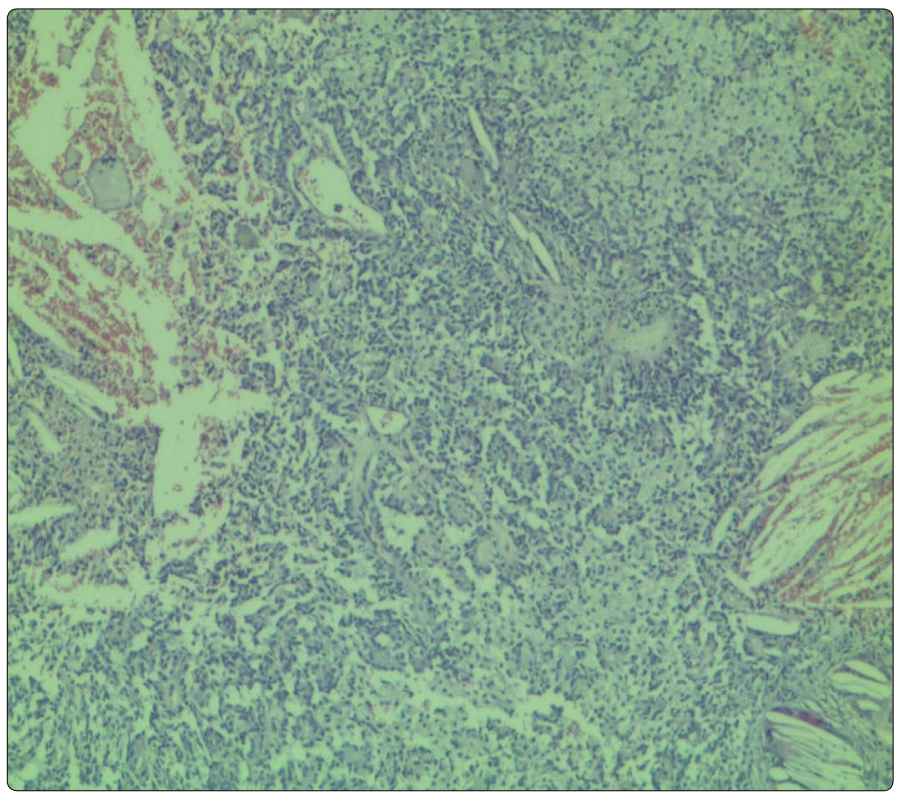

Figure 4. Pseudopapillary structures.

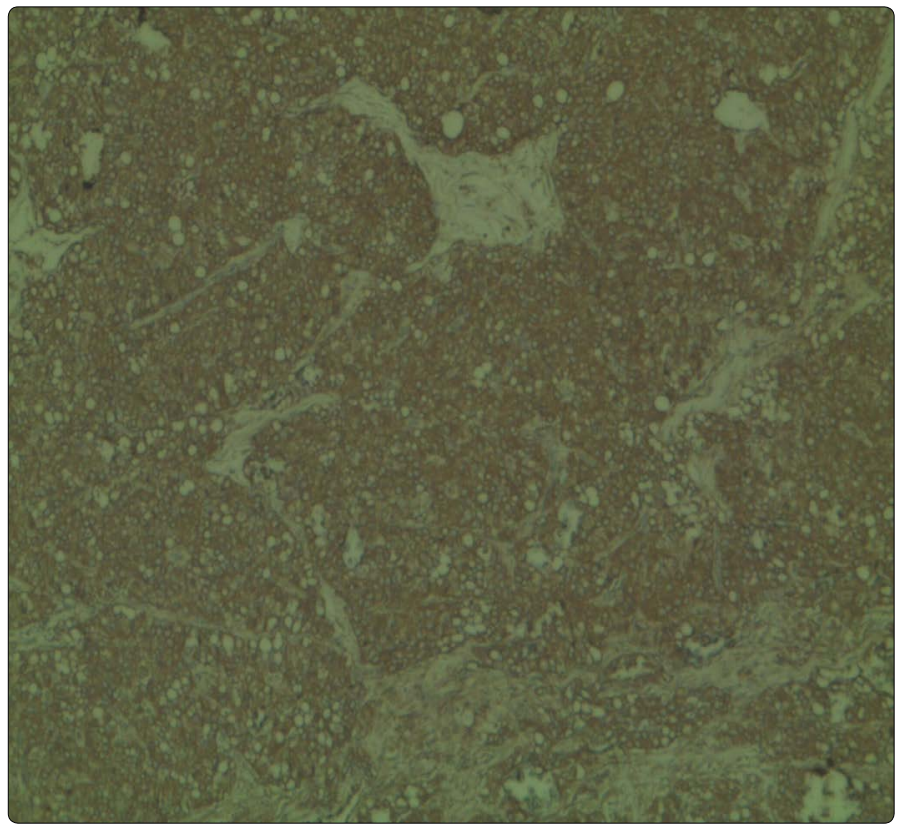

Figure 5. Expression of Vimentin in SPTT.

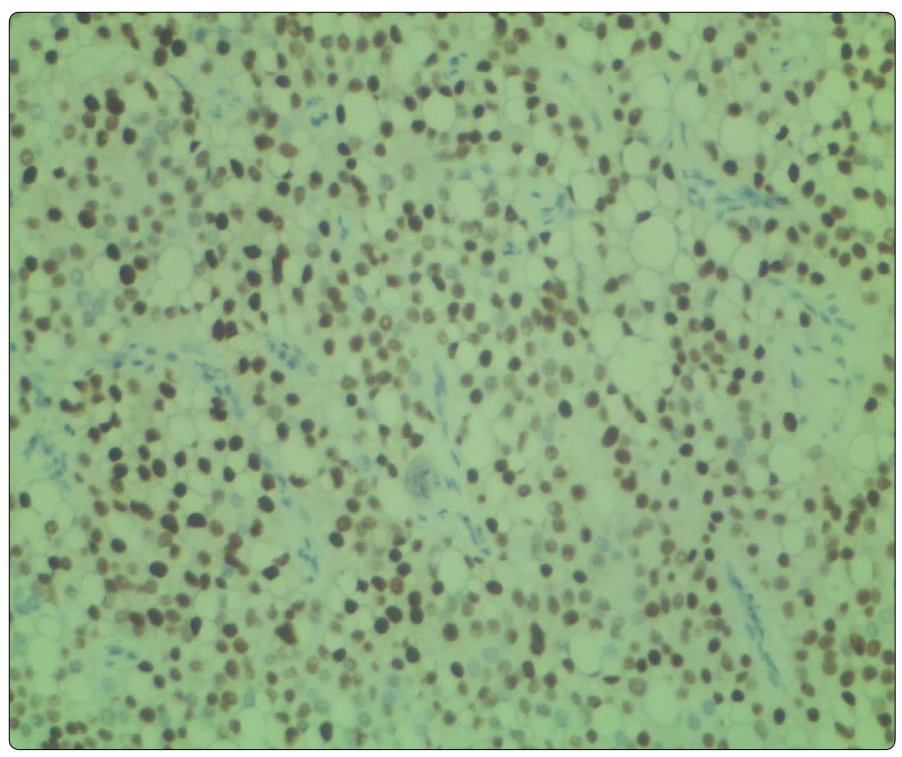

Figure 6. Progesteron expression in SPTT.

\section{Case 3}

46-year-old woman with complaints of pain in her upper abdomen, nausea and vomiting. History of hypothyroidism, ischemic heart disease, hysterectomy and bilateral adnexectomy for ovarian cancer over 8 years. From the physical examination a febrile, normal values of arterial pressure and pulse, pain in deep palpation in upper abdominal half.

From the abdominal ultrasonography and $\mathrm{CT}$ imaging data for a body-tail tumor with approximate size 50/30 mm with hyperehogenic content, which has compression on pancreatic duct, that has been dilated up to $4 \mathrm{~mm}$.

Intra-operatively: Increased pancreatic dimensions with cystic lesion in the body area and peripancreatic inflammatory collection - abscess, with necrotic areas. Specimen taken for microbiological examination - isolated Staphylococcus haemolyticus. A resection of the altered part of the pancreas was performed. No complaints in the next 3 months.

\section{Discussion}

Primary tumors of the exocrine pancreas are extremely rare in children. Warthin (1952) described embryonic carcinoma in a 15 year old boy, and later 8 more cases of cancer and two cases of lymphosarcoma of the pancreas in children. Frable described a specific type of pancreatic cancer in young, which he called "papillary carcinoma of the children's pancreas" $[3,4]$.

SPPT was established by Frantz in 1959-described three patients and recognized the special characteristics of the tumor. In the world medical literature were described more than 718 cases-Europe, USA and Japan (reviewed by Papavramidis et al. [5]) and 553 cases in Chinese literature (Peng-Fei Yu et al. [6]). Hamoudi et al. [7] and Kloppel et al. [8] suggested its differentiation as a separate tumor. SPT accounts for 1 to $2 \%$ of all exocrine pancreatic tumors [9].

Clinical presentation of the tumor is usually nonspecific even sometimes asymptomatic. Upper abdominal discomfort with uncharacteristic vague abdominal pain. Tumor can be found in any part of the pancreas, but most commonly located in the body and tail. Obstructive jaundice is extremely rare, even in the location at the head of the pancreas. Most common found in young females (especially between 20 and 30 years of age) [10], less frequently in older women as well as in males, usually slow-growing and with indolent course. Palpable abdominal mass (gradually enlarging) is one of the main clinical symptoms. In most cases this type of tumor is found after trauma caused bleeding from the tumor mass and/or abdominal discomfort. Acute manifestations are rare but should be kept in mind $[11,12]$.

SPPT usually well-demarcated tumor, with a diameter ranging from 1.5 to $30 \mathrm{~cm}$ (average $10 \mathrm{~cm}$ ). In our cases sizes were $-8.5 / 6.0 / 4.2 \mathrm{~cm}, 5.0 / 6.0 \mathrm{~cm}$ and $5.0 / 3.0 \mathrm{~cm}$ (Figures 1, 2, 7 and 8). 


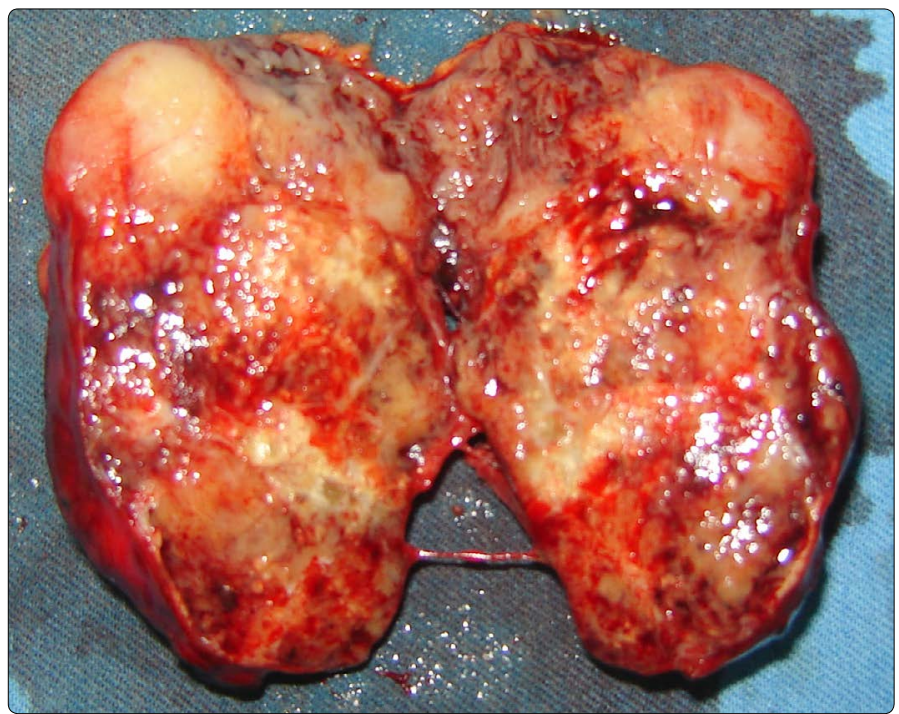

Figure 7. Postoperative specimen - heterogeneous appearance - solid, cystic and hemorrhagic areas.

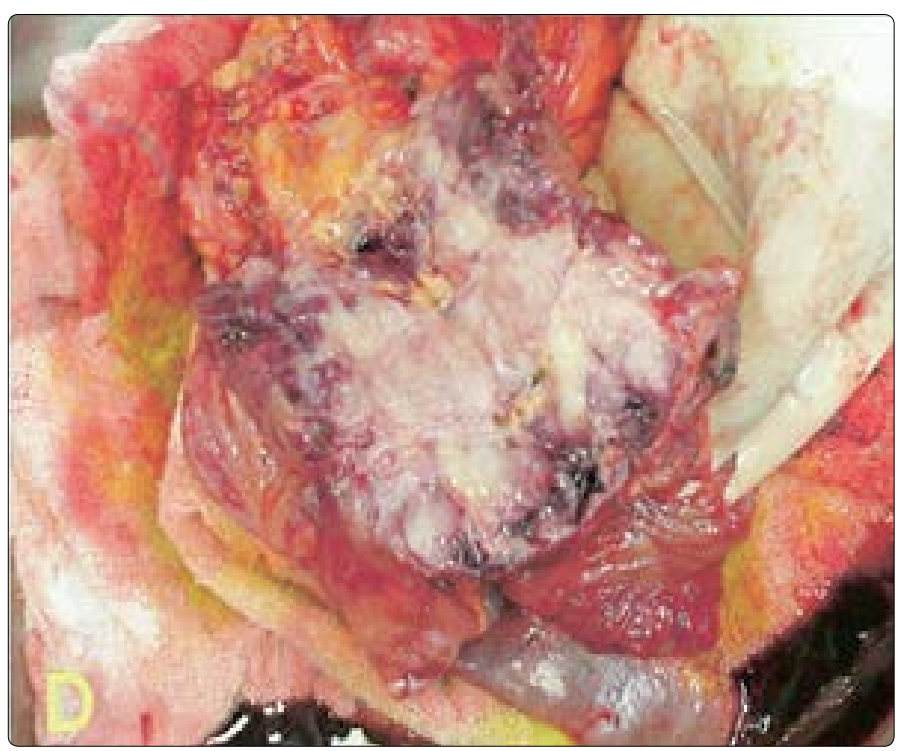

Figure 8. Gross appearance of postoperative specimen - solid and hemorrhagic areas.

The tumor is soft, yellow-red in color and contains solid and cystic areas. Hemorrhages, areas of cystic degeneration and irregular cystic walls can be observed. Microscopically cells are characterized by the same polygonal shape, with eosinophilic and vacuolar cytoplasm, around and often grooved ovoid nucleus, containing a nucleolus and dispersed chromatin. The nuclei are round or wrinkled, sometimes enlarged and irregular [13]. The stroma is vascularised with areas of bleeding hyalin aggregates of foamy histiocytes, cholesterol clefts, foreign body giant cells and hemorrhage. The most characteristic feature is the presence of pseudopapillary structures (Figure 3), covered by several layers of epithelial cells with pale eosinophilic cytoplasm and absence of glycogen and mucin. Pseudopapillary structures are formed by the disintegration of tumor cells in pseudocystic cavities. Quite often PAS-positive spherical cytoplasmic inclusions are found. Mitotic index and Ki67 are usually low, emphasizing the low malignancy rate of the tumor [14]. Electron-microscopic appearance - signs of glandular, tubular and endocrine structures. The most striking ultrastructural feature is the presence of focally abundant, variably sized electron-dense granules. Another commonly documented feature is the presence of cytoplasmatic annulated lamellae [15].

Diagnosis of this type of neoplasm easily can be established by FNA biopsy under US or CT control $[16,17]$. Obtained in this manner cytological diagnosis is often difficult in terms of differential diagnosis with pancreatic neuroendocrine tumors (as it was in our patients).

The origin of SPPT is still unknown and remains enigmatic. Most scientists believe it originates from multipotent primary stem cells. Immunohistochemical profile of SPT does not meet any of the pancreatic cells. Vimentin expression is common->90\% (Figure 6), suggesting that perhaps SPT are with mesenchymal origin, rather than epithelial tumors of the pancreas [18]. Expression of $\alpha 1$-antitrypsin (characteristic for pancreatic adenocarcinomas and NETs), is weak and nonspecific. Cytokeratin expression varies in different studies from $30 \%$ to $60 \%$, making the assignment of SPPT epithelial tumors difficult. Increased activity of neuron specific enolase (NSE), the absence of hormone synthesis or some endocrine dysfunction indicates that SPT cannot be defined as NET, although typical neuroendocrine differentiation [19]. Also an increased reactivity of specific markers for epithelial ductal carcinomas as CA 19-9 and CEA was not found in those patients [20]. The results indicate that SPPT cannot be attributed to epithelial ductal carcinomas. It is assumed that during embryogenesis, particularly the nervous system forming cells, come into contact with the pancreas and produce a new line of differentiation, leading to speculation that SPPT derived from these cells.

Although capsular, vessel and nervous invasion, nuclear pleomorfizam and the presence of mitotic activity suggests aggressive behavior of the tumor, it is sometimes difficult to put histopathological criteria, suggesting malignant potential. Nishihara et al. [21] reported that the venous invasion, diffuse growth pattern, extensive tumor necrosis, significant nuclear atypia and the high mitotic rate are indicative of aggressive behaviour. Metastases are described in about $12-15 \%$ of cases-liver and peritoneum, liver metastases $7 \%-9 \%$ of the cases. The lungs and skin may also be affected by metastases. Recurrence rate $2 \%$ to $6 \%$, usually due to infiltration into adjacent organs and structures. Even in cases of metastasis there is a long survival rate [22,23].

The curative treatment of SPPT is surgical: distal pancreatectomy (with or without splenic preservation), pancreato-duodenectomy, local resection or enucleation are the most common procedures. Extensive lymphatic dissection is not indicated in most of the cases. For the metastases there is also general consensus that surgical debulking could be performed (in contrast to pancreatic cancer). Laparoscopic surgery, seems to be attractive, especially in patients with distal location and small size of the tumor. In our case we performed middle pancreatic resections with pancreatogastric anastomosis. Local invasion, limited metastases or recurrence of the disease are not contraindications for resectional surgery [24]. 
Overall, prognosis is good, even after limited resections, because of its indolent growth. Even in the presence of disseminated disease, the clinical course is usually protracted and overall 5 -year survival rate is more than $65 \%$ [25].

Since in patients with SPT good prognosis is expected it is very important to differentiate between the ductal adenocarcinoma by and NETs. Typical macro-and microscopic features make this differential diagnosis quite easy. Ductal carcinoma (composed of tubules and gland structures) is more common in older men and is usually much smaller than SPPT. Neuroendocrine tumors usually are solid mass, and complications such as bleeding and pseudocysts are not typical. Microscopic nuclei are small, round, with smooth contours [26].

\section{Conclusions}

Solid pseudopapillary tumor of the pancreas is a rare primary neoplasm with unknown etiology, developing most commonly in young females. It is characterized by a paucity of clinical symptomatology, and can reach large sizes before final diagnosis. SPPT has a good prognosis, but potentially aggressive character, radically curable with surgery, easily distinguished from other tumors with similar location because of its characteristic clinical and histopathologic features. Literature review supports the concept that although the large size and locally invasion radical surgical resection offers chance of cure and benefits in almost all of the patients. Prognosis even for patients with SPPT and with treated liver metastases varies from 6 months up to more than 15 years. The role of chemotherapy, radiotherapy, TAE, TACE, radiofrequency is still under scrutiny.

\section{References}

1. Madiba TE, Ramdial PK, Pirie F. Solid and cystic papillary epithelial neoplasms of the pancreas. A report of 3 cases. S Afr J Surg. 2000; 38(3): 58-60.

2. Kosmahl M, Seada LS, Jänig U, Harms D, Kloppel G. Solid pseudopapillary tumor of the pancreas: its origin revisited. Virchows Arch. 2000; 436(5): 473-480.

3. Casanova M, Collini P, Ferrari A, Cecchetto G, Dall'Igna P, Mazzaferro V. Solid psudopapillary tumor of the pancreas (Frantz tumor) in children. Med Pediatr Oncol. 2003; 41(1): 74-76. doi: 10.1002/mpo.10289

4. RebhandI W, Felderbauer FX, Puig S, et al. Solid-pseudopapillary tumor of the pancreas (Frantz tumor) in children: report of four cases and review of the literature. J Surg Oncol. 2001; 76(4): 289-296.

5. Papavramidis T, Papavramidis S. Solid pseudopapillary tumors of the pancreas: review of 718 patients reported in English literature. J Am Coll Surg. 2005; 200(6): 965-972. doi: 10.1016/j.jamcollsurg.2005.02.011

6. Peng-Fei $Y$, Zhen-Hua $H$, Xin-Bao W, et al. Solid pseudopapillary tumor of the pancreas: A review of 553 cases in Chinese literature. World $J$ Gastroenterol. 2010: 16(10): 1209-1214. doi: 10.3748/wjg.v16.i10.1209

7. Hamoudi AB, Misugi K, Grosfeld JL, Reiner CB. Papillary epithelial neoplasm of pancreas in a child. Report of a case with electron microscopy. Cancer. 1970; 26(5): $1126-1134$. doi: 10.1002/1097-0142(197011)26:5<1126::aidcncr2820260524>3.0.co;2-k

8. Klöppel G, Morohoshi T, John HD, et al. Solid and cystic acinar cell tumor of the pancreas. A tumor in young women with favorable prognosis. Virchows Arch A Pathol Anat Histol. 1981; 392(2): 171-183.
9. Sheeham $M$, Latona $C$, Aranha G, Pickerman J. The increasing problem of unusual pancreatic tumors. Arch Surg. 2000; 135(6): 644-648. doi: 10.1001/ archsurg.135.6.644

10. Chung EM, Travis MD, Conran RM. Pancreatic tumors in children: radiologic-pathologic correlation. Radiographics. 2006; 26(4): 1211-1238. doi: 10.1148/rg.264065012

11. Bassi C, Salvia R, Molinari E, Biasutti C, Falconi M, Pederzoli P. Management of 100 Consecutive Cases of Pancreatic Serous Cystadenoma: Wait for Symptoms and See at Imaging or Vice Versa? World J Surg. 2003; 27(3): 319-323. doi: 10.1007/s00268-002-6570-7

12. Cervantes-Monteil F, Florez-Zorilla C, Alvarez-Martinez I. Solid-cystic pseudopapillary tumor of the pancreas:acute post traumatic presentation. Case report and review of the literature. Rev Gastroenterol Mex. 2002; 67(2): 93-96.

13. Rosai J. Ackerman's Surgical Pathology. 9th edition. Missouri: Mosby; 2004.

14. Brozzetti S, French D, Polistena A, et al. Papillary solid and cystic pancreatic tumor. Genetic prediction factors for malignancy:report of three cases. Anticancer Res. 2002; 22(4): 2341-2356.

15. Klimstra DC, Wenig BM, Hefess CS. Solid pseudopapillary tumor of the pancreas: a typically cystic carcinoma of low malignant potential. Semin Diagn Pathol. 2000; 17(1): 66-80.

16. Cantisani V, Mortele KJ, Levy A, et al. MR imaging features of solid pseudopapillary tumor of the pancreas in adult and pediatric patients. AJR Am J Roentgenol. 2003; 181(2): 395-401. doi: 10.2214/ajr.181.2.1810395

17. Lee $\mathrm{DH}, \mathrm{Yi} B \mathrm{BH}$, Lim JW, Ko YT. Sonographic findings of solid and papillary epitheliail neoplasms of the pancreas. J Ultrasound Med. 2001; 20(11): 1229-1232.

18. Notohara K, Hamazaki S, Tsukayama C, et al. Solid pseudopapillary tumor of the pancreas: immunohistochemical localization of neuroendocrine markers and CD10. Am J Surg Pathol. 2000; 24(10): 1361-1371.

19. Canzonieri V, Berretta $M$, Buonadonna $A$, et al. Solid pseudopapillary tumor of the pancreas. Lancet Oncol. 2003; 4(4): 255-256.

20. Martin RC, Klimstra DS, Brennan MF, Conlon KC. Solid pseudopapillary tumor of the pancreas: A surgical enigma? Ann Surg Oncol. 2002; 9(1): $35-40$.

21. Nishihara K, Nagoshi M, Tsuneyoshi M, Yamaguchi K, Hayashi I. Papillary cystic tumors of the pancreas. Assessment of their malignant potential. Cancer 1993; 71: 82-92.

22. Pambuccian SE, Somma P, Insabato L. Solid-pseudopapillary tumor of the pancreas: a neoplasm with distinct and highly characteristic cytological features. Diagn Cytopathol. 2002; 27(6): 325-334. doi: org/10.1002/ dc.10189

23. Washington K. Solid pseudopapillary tumor of the pancreas: challenges presented by an unusual pancreatic neoplasm. Ann Surg Oncol. 2002; 9(1): 3-4.

24. Sheeham MK, Beck K, Pickerman J, Aranha GV. Spectrum of cystic neoplasms of the pancreas and their surgical management. Arch Surg. 2003; 138(6): 657-660. doi: 10.1001/archsurg.138.6.657

25. Petrakis I, Vrachassotakis N, Kogerakis N, Hatzidakis A, Zoras $O$, Chalkiadakis G. Solid pseudopapillary neoplasm of the pancreas: report of a case after 10-year follow-up and review of the literature. Pancreatology. 2001; 1(2): 123-128. doi: 10.1159/000055804

26. Lai R, Stanley MW, Bardales R, Linzie B, Mallery S. Endoscopic ultrasoundguided pancreatic duct aspiration: diagnostic yield and safety. Endoscopy. 2002; 34(9): 715-720. doi: 10.1055/s-2002-33443 